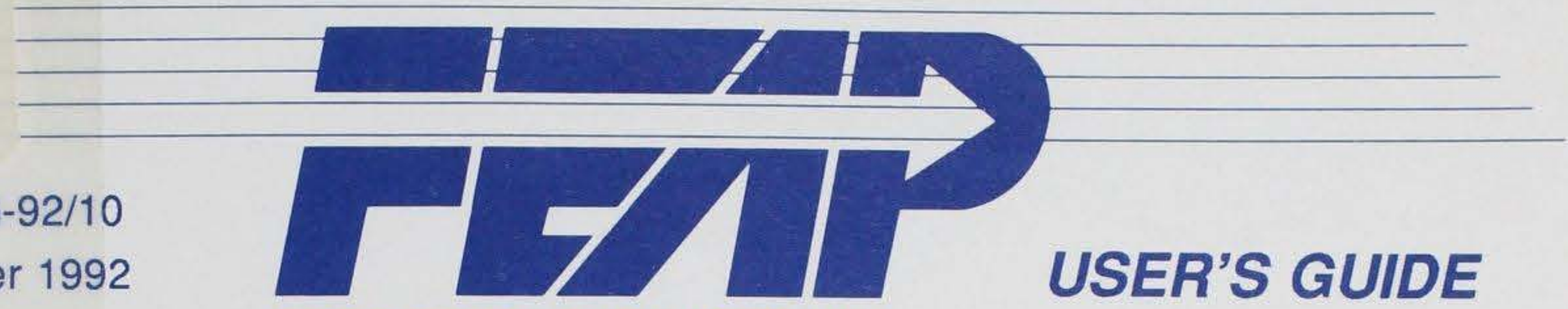

\title{
USER'S GUIDE: PAVEMENT MARKINGS
}

\section{US-CE-C propepty of the \\ UNITED STATES GOVERNMENT}

by

Larry N. Lynch

US Army Engineer Waterways Experiment Station

Vicksburg, MS 39180-6199

RESEARCH LIBRARY

US ARMY ENGINEER WATERWAYS

EXPERIMENT STATION

VICKSBURG, MISSISSIPPI

Approved For Public Release; Distribution Is Unlimited

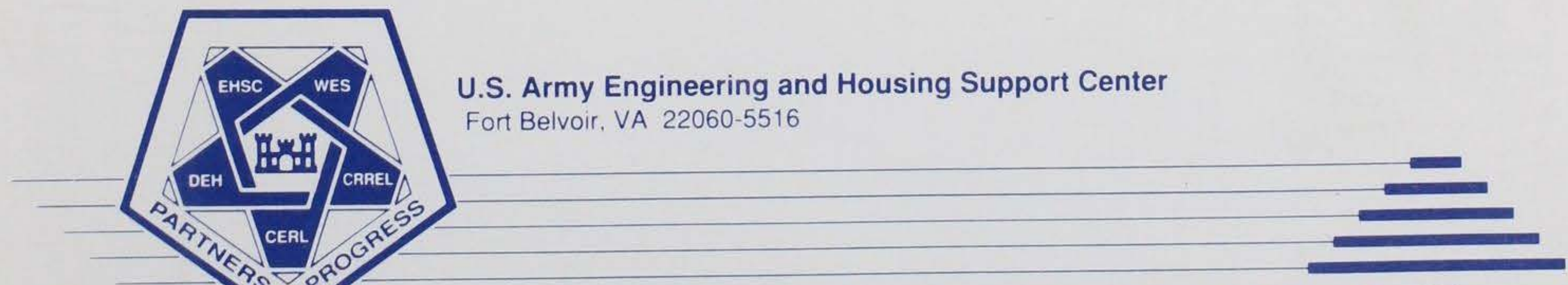

Innovative Ideas for the Operation, Maintenance, \& Repair of Army Facilities 
Public reporting burden for this collection of information is estimated to average 1 hour per response, including the time for reviewing instructions, searching existing data sources gathering and Davis Highway, Suite 1204, Arlington, VA 22202-4302, and to the Office of Management and Budget, Paperwork Reduction Project (0704-0188), Washington, DC 20503.

\begin{tabular}{|l|l|l|l}
\hline 1. AGENCY USE ONLY (Leave blank) & $\begin{array}{l}\text { 2. REPORT DATE } \\
\text { September 1992 }\end{array}$ & $\begin{array}{c}\text { 3. REPORT TYPE AND DATES COVERED } \\
\text { Final report }\end{array}$ \\
\hline
\end{tabular}

4. TITLE AND SUBTITLE
User's Guide: Pavement Markings

\section{AUTHOR(S)}

Larry N. Lynch

\section{PERFORMING ORGANIZATION NAME(S) AND ADDRESS(ES)}

USAE Waterways Experiment station

Geotechnical Laboratory

3909 Halls Ferry Road

Vicksburg, MS 39180-6199

\section{SPONSORING / MONITORING AGENCY NAME(S) AND ADDRESS(ES)}

US Army Corps of Engineers Engineering and Housing Support Center Bldg. 2593

Fort Belvoir, VA 22060-5516

\section{FUNDING NUMBERS}

\section{SUPPLEMENTARY NOTES}

\section{2a. DISTRIBUTION/AVAILABILITY STATEMENT}

Approved for public release; distribution

is unlimited.

8. PERFORMING ORGANIZATION REPORT NUMBER

Miscellaneous Paper GL-92-29

10. SPONSORING / MONITORING AGENCY REPORT NUMBER

FEAP-UG-92/10

is unlimited.

\section{ABSTRACT (Maximum 200 words)}

This report documents the Facilities Engineering Applications Program project "Pavement Markings" which was conducted from FY88 to FY90. Two sites, Fort Bragg, NC, and Fort Lewis, WA, were selected for demonstrating techniques used to install various types of pavement markings. A brief description of the types of pavement markings and the different considerations used to select a marking type are presented.

\begin{tabular}{|c|c|c|c|}
\hline $\begin{array}{l}\text { 14. SUBJECT TERMS } \\
\text { Pavement marking } \\
\text { Pavement tapes } \\
\text { Raised reflectiv }\end{array}$ & markings & $\begin{array}{l}\text { Therl } \\
\text { Traf: } \\
\text { Traf: }\end{array}$ & $\begin{array}{l}\text { oplastic marking } \\
\text { ic markings } \\
\text { ic paints }\end{array}$ \\
\hline $\begin{array}{l}\text { 17. SECURITY CLASSIFICATION } \\
\text { OF REPORT } \\
\text { Unclassified }\end{array}$ & $\begin{array}{l}\text { 18. SECURITY CLA } \\
\text { OF THIS PAGE } \\
\text { UnClass }\end{array}$ & $\begin{array}{l}\text { ICATION } \\
\text { ied }\end{array}$ & $\begin{array}{l}\text { 19. SECURITY CLASSIFICATION } \\
\text { OF ABSTRACT } \\
\text { UnClassified }\end{array}$ \\
\hline
\end{tabular}




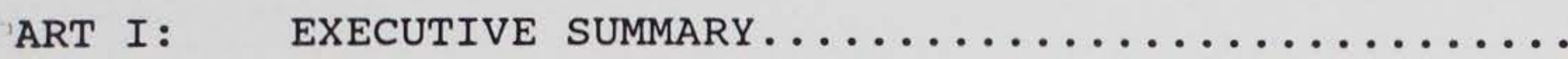

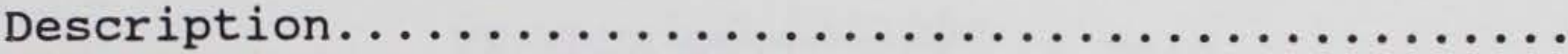

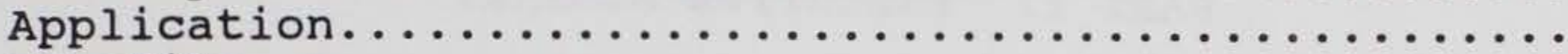

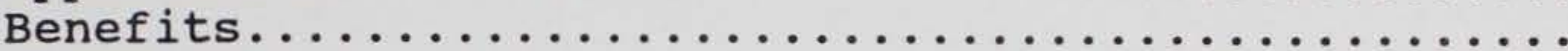

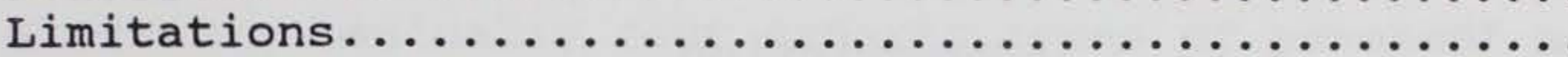

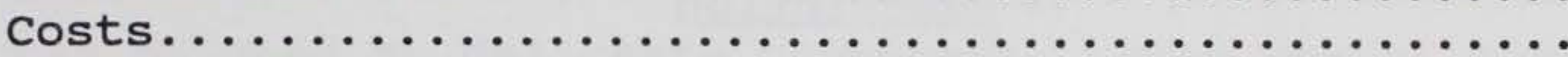

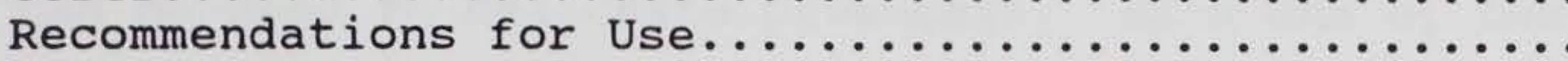

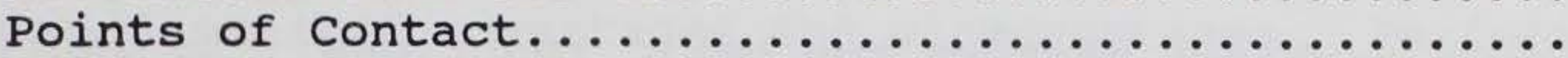

PART II: PREACQUISITION...................... 5

Description of Pavement Markings................ 5

Considerations for Selecting a Pavement Marking...... 5

Description of Pavement Preparation Techniques....... 15

Description of Pavement Marking Techniques........... 24

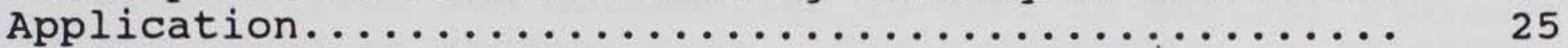

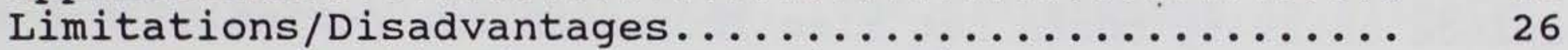

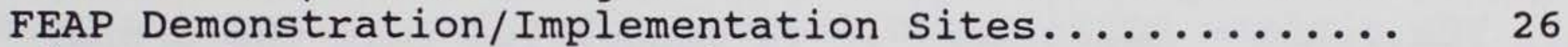

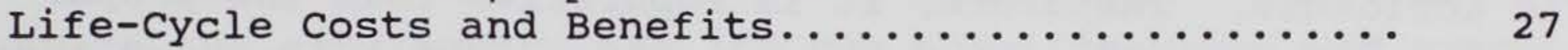

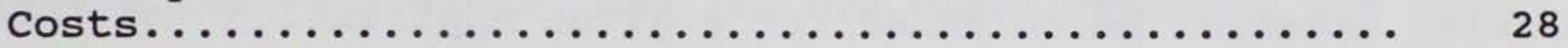

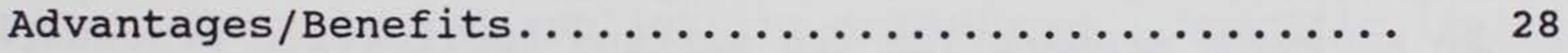

PART III: ACQUISITION/PROCUREMENT.................. 29

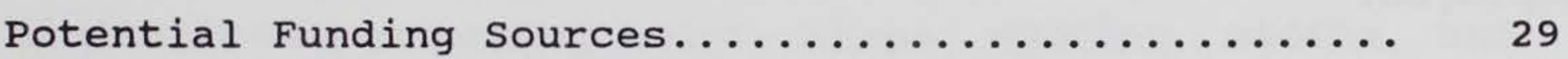

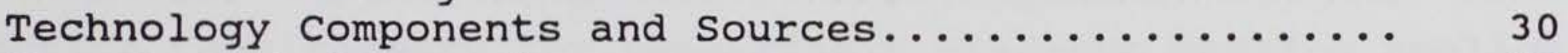

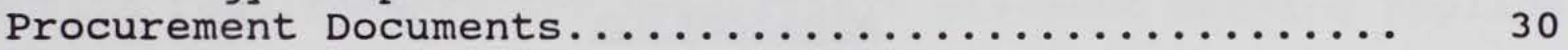

Procurement Scheduling..................... 30

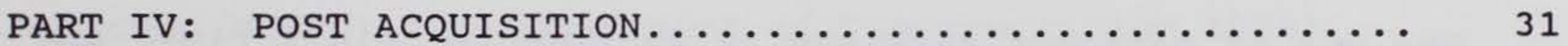

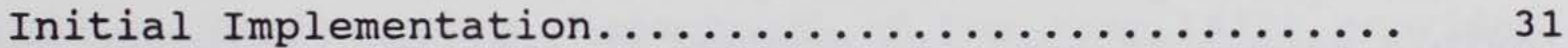

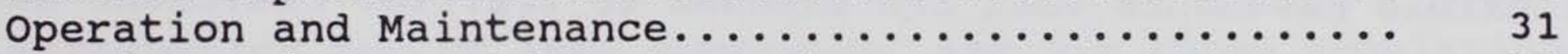

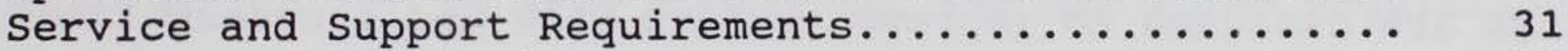

Performance Monitoring..................... 32

PHOTOS $1-6$

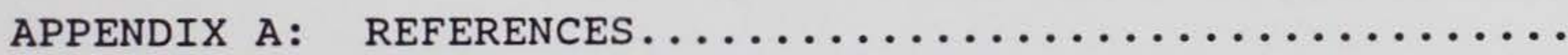




\section{USER'S GUIDE: PAVEMENT MARKINGS}

\section{PART I: EXECUTIVE SUMMARY}

\section{Description}

Pavement markings perform two basic functions: to improve traffic flow and increase vehicle and pedestrian safety. To perform these functions, they must remain visible in both daylight and nighttime conditions and in inclement weather. Premature failure or loss of delineation not only increases maintenance activity costs but also increases the potential for traffic accidents. Therefore, it is imperative that the proper marking material be selected for a given application and that the proper pavement preparation and marking application procedures be employed.

\section{Application}

The use of pavement markings is applicable to all rigid and flexible pavements that are exposed to traffic. Pavement markings are designed to improve traffic flow and increase traffic and pedestrian safety by providing directional guidance and regulatory and warning information.

\section{Benefits}

The use of pavement markings increases traffic and pedestrian safety. Therefore, by selecting the appropriate marking material and by employing the proper techniques for pavement surface preparation and marking application techniques, the lifecycle cost and maintenance costs to maintain delineation can be decreased. The actual financial benefits realized by the use of this technology will be dependent upon the individual installation. However, if as a minimum the life of the markings can be 
doubled, a significant savings in funds currently obligated for marking projects could be realized.

\section{Limitations}

There are basically four generic types of pavement markings that can be used to delineate pavements. Each one of the marking types will exhibit advantages and disadvantages. Performance evaluations conducted by state agencies have presented conflicting results indicating that a pavement preparation technique or marking application procedure that provides acceptable results in one state, county, or city may provide totally unacceptable results when used in another area. The differences in climate, pavement substrate, and environmental constraints explain why each state and city agency has its own specifications and practices for materials and application procedures. Specific limitations or disadvantages will be discussed in PART II.

Limitations concerning color, shape, spacing, widths, and reflective requirements for nonairfield pavement marking applications are provided in the Manual on Uniform Traffic Control Devices (MUTCD) (US Department of Transportation 1988). TM 5-823-4 (Headquarters, Department of the Army 1987) provides this information for US Army airfields, and Air Force Regulation AFR 88-16 (Headquarters, Department of the Air Force 1988) provides this information for US Air Force airfields.

\section{Costs}

The cost of the installed marking material will vary depending upon the type of marking that is selected. Paints typically cost approximately $\$ 0.03$ per linear foot for a 4-inch strip, thermoplastics cost approximately $\$ 0.40$ per linear foot for a 4-inch strip, and tapes typically cost approximately $\$ 1.25$ per linear foot for a 4-inch strip. 


\section{Recommendations for Use}

The use of this technology is recommended in construction, reconstruction, and/or rehabilitation of pavement structures.

\section{Points of contact}

Points of contact regarding this technology are:

Technical:

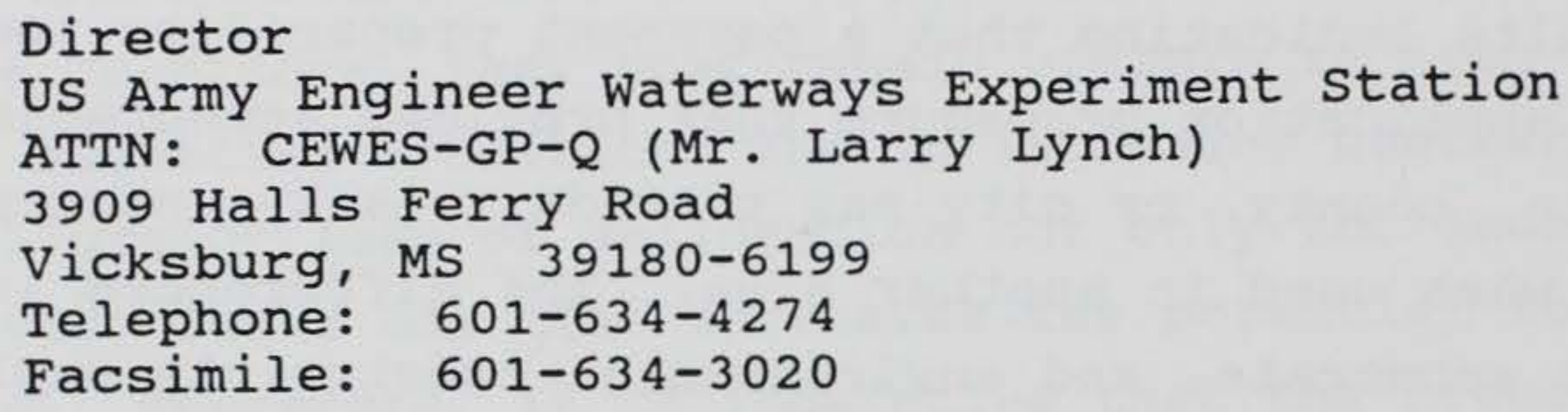

US Army Engineering and Housing Support Center:

Commander

US Army Engineering and Housing Support Center

ATTN: CEHSC-FB-P (Mr. Joseph Sicuranza)

Fort Belvoir, VA 22060-5516

Telephone: 703-704-1581/1574

Facsimile: 703-780-5935

The points of contact at the Facilities Engineering Application Demonstration (FEAP) sites located at Fort Bragg, NC, and Fort Lewis, WA, are:

\section{Commander}

XVIII Airborne Corps, Fort Bragg

Directorate of Engineering and Housing

ATTN: AFZA-DE-EC (Mr. Rob Harris)

Fort Bragg, NC 28307-5000

Telephone: 919-369-1920

Commander

Headquarters I Corps, Fort Lewis Directorate of Engineering and Housing ATTN: AFZH-DEP-P (Mr. MarV Schoch)

Fort Lewis, WA 98433-5000

Telephone: 206-967-6375 


\section{Description of Pavement Markings}

Pavement markings provide two very essential roles in every pavement system whether the pavement system is an airfield, a highway, a roadway, or a grocery store parking lot. The pavement markings are designed to improve traffic flow and increase traffic and pedestrian safety. Traffic markings provide directional guidance as the means of improving traffic flow, while regulatory and warning information provided by the markings improve safety.

It has been estimated that over $37,000,000$ gallons $\left(140,000 \mathrm{~m}^{3}\right)$ of traffic paint, 55,000 tons $(50,000 \mathrm{mg})$ of pavement thermoplastics, 130,000 tons $(118,000 \mathrm{mg})$ of glass beads, and an unknown quantity of raised, recessed, thermosetting and tape markings are used annually in the United States (National Cooperative Highway Research (NCHRP) 1988). A great percentage of the pavement markings used annually are used to remark failed areas or areas that have insufficient delineation.

Pavement marking failures can be attributed to one of several factors; however, the ones that can be controlled by field personnel are the pavement surface preparation and marking application procedures.

There are basically four generic types of markings used to delineate pavements. The four types of pavement markings are paints, thermoplastics, tapes, and raised reflective markers.

\section{Considerations for Selecting a Pavement Marking}

Each type of marking material has advantages and disadvantages, and, therefore, several items must be considered before the best marker for a given application can be selected. The items which must be considered are:

a. Climatic region.

b. Cost of marking versus expected life.

c. Location and function of the marking on the pavement. 
d. Average daily traffic (ADT) and type of traffic.

e. Pavement type.

f. Availability of equipment and labor.

These items are interrelated and must be considered as a group instead of individually. The most critical item from the list will be dependent upon the user agency.

The climatic region in which the marker will be used can have a great impact in the selection criteria. For example, in warmer regions some thermoplastics may become unstable due to high pavement temperatures, and some binder materials in markers rapidly deteriorate when exposed to ultraviolet (UV) radiation. At the opposite extreme, in cold climates marking materials may become brittle and crack as temperatures drop. Another cold climate consideration is the use of snow plows. As snow is removed from a pavement, the snow plow blade can remove thick pavement markers in addition to the snow.

Some of the more durable pavement markings have a greater initial cost, and they are not normally considered for application by some agencies. However, life cycle and maintenance costs should also be considered. Unfortunately, the availability of funding is often the limiting factor which requires a less expensive initial cost material to be selected.

The function of the marker (center line, fog line or edge line, stop bar, cross walk, etc.) affects selection criteria. A center line receives much more abrasion due to traffic than a fog line; so a more durable material is required for the center line. stop bars and cross walks are abraded by normal moving traffic but are also abraded by accelerating and decelerating traffic. If the markers are not adequately bonded to the pavement, traffic movement can cause tapes and thermoplastics to become deformed and damaged.

It is logical to expect that the number of vehicles or ADT and the type of traffic to which a marking is exposed will be a vital consideration in selecting a marker. A more durable marking is required for larger ATD's and for areas that are exposed 
to tracked traffic, i.e., tanks and heavy equipment, and a less 'urable marking may be considered for rural roads.

once the "items of consideration" have been examined and understood, the advantages and disadvantages of each marker type should be examined. Since each type of marker will perform differently, the best method of selecting pavement markings is to require test sections. This is not always practical for a military installation, but the local state Department of Transportation (DOT) will normally have performance evaluations of various materials that have been used on state projects. Specific advantages and disadvantages are discussed in later sections.

In considering the question of "what works best," a questionnaire survey was conducted by "Better Roads" (Better Roads 1989) in 1989 which had approximately 200 readers to respond. one question asked was which materials actually used by the responding department performed the best in all applications. Approximately 32.3 percent stated that traffic paints performed the best for all applications, 30.2 percent stated that preformed tapes performed the best, and 28.1 percent stated thermoplastics performed the best. Another question asked was which material does the responding agency believe performs the best. This question did not limit the selection to materials used by the agency. Approximately 36.5 percent of those who responded believed that thermoplastics performed the best, and paints and preformed tapes received considerable lower percentages; 19.8 percent and 14.6 percent, respectively. This survey reiterates the fact that no one material either performs or perceives to perform the best in all situations.

If a particular material cannot be selected to perform well in all situations, what can be done to get the most out of a material once it is selected? To ensure maximum performance of a given marker, it is imperative that the material be placed to the pavement under ideal conditions.

\section{Traffic paints}

Paints, first used in Michigan around 1911 (Organization for Economic Co-operation and Development 1975), have been used 
longer than any other material for marking pavements and exceed all other materials combined in roadway mile usage. Because of the wide use of paints, they are the cost and performance standard used to compare all other marking types.

There are several methods that may be employed to classify paints. The paints may be classified by reflectance; reflective or nonreflective, method of application; hot or cold, type of base material, or drying time. The reflectance classification indicates if a reflective media has been added to enhance delineation. There are four base materials from which a paint is normally manufactured and classified. The four base materials are an alkyd resin or oil base, a rubber base which is usually a chlorinated rubber, a drying oil varnish or modified alkyd known as oleoresin, and water based materials (US Department of Transportation 1981). The first three types listed are solvent-borne which is the most common type of paint used today; however, due to environmental concerns water-borne or water based paints are being used more and more.

The last classification, drying time, is dependent upon the method of application, the chemical composition, and the pavement temperature. The following categories of drying times are normally used to classify paints (US Department of Transportation 1981) :

a. Conventional - drying time ranges from 7 minutes to several hours. These are cold applied materials and the specific drying time will be dependent upon atmospheric conditions, film thickness, and road condition.

b. Fast dry - obtain tack free or no-track condition within 2 to 7 minutes. These materials are normally hot applied materials.

c. Quick dry - obtain a no-track condition in 30 to 120 seconds. These materials are hot applied.

d. Instant dry - obtain a no-track condition within 30 seconds. These materials are heavily bodied, hot applied paints.

The obvious advantage of faster drying times is the fact that traffic can be allowed on the pavement sooner.

Solvent-borne paints normally consist of approximately 25 percent by volume of pigment, extender, and filler, 25 percent 
by volume of binder, and 50 percent by volume of solvent. The type of pigment used will depend upon the desired color. Titanium dioxide pigment is used for white paints, and lead chromate has been used for yellow paints, both of which are inorganic materials. The use of organic pigments in yellow paint has been investigated in recent years because of the potential health hazards associated with lead chromate. The organic pigments normally are much more expensive than lead chromate and have had a tendency to fade more rapidly than lead chromates.

Inert materials such as calcium carbonate and silica products are the most common type of extenders and fillers used in paints, and the binder can be a composition of up to 10 different ingredients. In solvent-borne paints, the most common types of binder and the most cost-effective are alkyd resins or chlorinated rubber modified alkyd resins to which antiskinning agents and dryers are added. Each ingredient of the paint plays a determining role in the durability and service life of the paint, but the binder resin is the most critical.

The remaining 50 percent of the paint by volume is solvent or thinner which adds nothing to the integrity or service life of the dried paint film. This means that half of each gallon of paint remains on the pavement and the other half evaporates into the air. The solvent is required to improve the sprayability of the paint, and the type of solvent used affects the drying time of the paint. These are important functions, but the idea of paying for a material of which 50 percent does not contribute to the final product and evaporates contaminating the atmosphere has led to the development of higher solids paints (NCHRP 1988). Water-borne or water based paints were introduced for pavement marking several years ago. However, because of their cost, extended drying time, and reduced performance as compared to solvent-borne paints, they were not widely accepted. In recent years, environmental regulations throughout the country and, in particular, California, have produced an increased interest in water based paints. 
Current water based paints use acrylic or latex resins and have drying times of about 10 minutes. Lead-free yellow pigmentation systems have been developed for the water based paints and waterproof glass beads are used. As a result of these developments, California DOT concludes that water based paints provide a service life equal to or better than solvent-borne paints, provide better bead retention, and have safer application characteristics than solvent-borne paints (NCHRP 1988). However, other agencies have not been as satisfied with these paints as california.

One advantage of solvent-borne traffic paints is that pavement preparation is not as critical for their performance as with other types of markers such as thermoplastics. The solvent in the paint reduces its viscosity and surface tension allowing it to more readily wet through or penetrate the road film and bond to the pavement.

\section{Thermoplastics}

Thermoplastics for use as pavement markings were developed before World War II (NCHRP 1988). Thermoplastics are solid at ambient temperature and become liquid at elevated temperatures. Thermoplastics do not contain solvents which give them a distinct advantage over solvent-borne traffic paints. Currently, thermoplastics use alkyd or hydrocarbon resins as the base material. Both of these base materials have very similar physical properties. Therefore, the selection of one versus the other is largely based on economics.

A typical pavement marking thermoplastic consists of approximately 18 percent by weight of resin, 25 percent glass beads, and 57 percent pigment and filler (NCHRP 1988). These materials are normally supplied in one of two forms. One form is a premixed material where the manufacturer melts the ingredient materials, blends them together, casts the thermoplastic into blocks, and allows the blocks to cool. The blocks are sold to the user who remelts the material and places it on the pavement. The second and most commonly supplied form is a granulated mixture. The manufacturer dry blends the required materials together and 
bags the blended material. The bags are sold to the user who dumps the bags into the melter for application to the pavement. The granulated material is less expensive since the manufacturer does not have the added cost of melting and blending.

Thermoplastics have proven to provide better delineation, (lane marking visibility) especially on rainy nights and have a longer life in warmer climates like Mississippi than do paints (US Department of Transportation 1976). However, their durability in colder regions has been a cause for concern.

one possible disadvantage of thermoplastics is the fact that some type of surface treatment or primer is often required to improve adhesion. The pavement surface preparation is a critical element in obtaining a long lasting thermoplastic marker. Reflective beads

Traffic paints and thermoplastics are not reflective unless a reflectorizing substance is added. During the daytime or in well lighted areas, reflective markings may not be essential. At night, during rainy or foggy weather, and in areas that are not well lighted, reflective markings are a critical safety aspect for traffic movement. The light of vehicular traffic shines on the reflective media. A portion of that light is redirected back to the driver in delineating driving lanes or providing warning signals.

Glass beads are currently the best system available to produce a reflective paint or thermoplastic because they provide two essential properties to refract and redirect light. The two properties are transparency and roundness. Transparency and roundness explain why light is reflected, but other characteristics determine the amount of light reflected. The amount of light reflected is dependent upon the number of beads in the pavement marking, the size and shape of the beads, the surface characteristics of the individual beads, and the index of refraction (US Department of Transportation 1981).

The number of glass beads available to reflect light is an obvious factor in determining the amount of reflective light. 
The greater the amount of reflective media available to the light source the greater the amount of reflection.

To understand why shape and surface characteristics are important, it is helpful to understand how transparency and roundness affect reflectivity. Transparency is an important characteristic because the light must pass into the bead before it can be reflected. If the surface is irregular or pitted, the light cannot enter. If no light enters, none is reflected. The roundness characteristic causes the entering light to be bent or refracted to a portion of the bead that is imbedded into the paint. The light bounces off of the paint coated portion of the bead and is directed back along the entry path similar to the way in which a mirror reflects light (US Department of Transportation 1981).

The size range or gradation of beads used with paints or thermoplastics plays an important role in both immediate and long term reflectivity. One study indicates (Bryden and Gurney 1984) that the maximum reflectivity is obtained when approximately 50 percent of the bead diameter is embedded into the marking material. Based on this fact, it appears that a uniform bead size of twice the marking thickness should be selected. However, as pavement markings age, beads and the marking material are abraded. As a result of abrasion, beads are dislodged from the marking material reducing the reflectivity. To compensate for wear and abrasion, a gradation band of beads is selected. Large beads are used to provide immediate reflectivity, and smaller beads are used to provide long term reflectivity. As larger diameter beads are dislodged, the smaller diameter beads are exposed and delineate the marked area. There is not a general consensus on the exact gradation that should be used for pavement markings; however, a typical application of drop-on beads ranges from No. 20 to No. 100 mesh.

The last function mentioned that regulates the degree of brightness is the refractive index (RI). The glass bead functions as a light-focusing lens and, like a lens, has a definite focal point. The focal point of a bead is a point outside the 
ead diameter from which the light seems to originate as it is reflected back towards the source. The position of the focal point is determined by the chemical composition of the glass bead and the closer the focal point is to the back surface of the bead, the brighter the light is reflected (US Department of Transportation 1981).

Beads used in traffic paints normally have an RI of 1.50 , while those used in thermoplastics normally have an RI of 1.65 . Glass beads used in marking airfields normally have an RI of 1.90. For comparison, the focal point of a bead with an RI of 1.50 is further behind the surface than one with an RI of 1.65 . The RI 1.90 glass bead has a focal point located almost on the surface.

Most states use glass beads which have an RI of 1.50 even though beads with an RI of 1.65 or 1.90 are more reflective. The main reason for the use of RI 1.50 beads is economics. The RI 1.50 beads are produced from recycled materials, and they exhibit more chemical stability with less weight (US Department of Transportation 1981) than the other beads.

Tapes

Pavement marking tapes are preformed materials produced at a factory and shipped to the project site in roll or cut-out legend form. Tapes generally consist of a resin binder, pigment, glass beads, and fillers (Bryden and Gurney 1984). An adhesive may be added to the back of the tape to secure the tape for placement or the adhesive may be a separate component which is applied to the pavement before the tape is placed on the pavement.

Tapes are classified into one of two categories: permanent or temporary. Permanent tapes are generally manufactured from plastic materials and temporary tapes, those used to detour traffic around construction areas, are usually a foil-backed material. It should be noted that this is a generalization since some foil-backed materials may be durable enough to be used as permanent markers.

The use of permanent pavement marking tapes has been increasing in recent years due to improved materials used in 
manufacturing the tapes and a reduction in the maintenance effort when the tapes are properly applied. An example of reduced maintenance effort is the fact that if a small portion of the tape becomes damaged or loose, maintenance crews can cut out the damaged area, apply some adhesive, and place new tape in a short period of time.

The initial cost of tapes are relatively high when compared to other types of markings, but when properly installed, the life-cycle cost is comparable to other markings. Pavement preparation is more critical for the field performance of tapes than some other marker types. For use as temporary markings, tapes are one of the easiest methods available.

\section{Raised markers}

Raised pavement markers or "buttons" are generally classified as reflective or nonreflective and are available in a wide variety of shapes, sizes, and types and are made from a wide variety of materials. There are two advantages of raised markers over other types of pavement markings. Both of the advantages are due to the fact that the markers are raised. The first advantage is that as a vehicle passes over the marker, a definite sound is produced which provides the driver with an audio warning as well as a visual warning. The second advantage is better delineation during rain. The raised markers are normally above the water level in the street and are therefore visible to the driver.

The most widely used nonreflective raised markers are produced from ceramic with a glazed surface. These markers resist abrasion and discoloration due to road film. Reflective raised markers usually are constructed using cube-cornered acrylic lenses, tempered glass lenses, or glass bead lenses, mounted in a plastic ceramic or metal base (NCHRP 1988).

When properly applied, raised markers are probably the most durable marker and provide the best night and wet pavement visibility. However, the durability of raised markers is greatly reduced in climates that require snow removal. Numerous problems 
have also been associated with the adhesive system used to place the markers on the pavement.

Several adhesive systems exist for use with raised markers. The systems range from two-component epoxy mixtures to hotapplied asphalt based materials. Often the manufacturer will recommend a particular system based upon the substrate to which the marker will be applied. For example, when raised markers were first introduced the majority of adhesive systems were epoxies which become brittle upon curing. These hard epoxies crated flexible pavements to deteriorate under the markers. As traffic would cross the raised marker, the impact of the vehicle tire on the marker would be transferred through the marker/ adhesive system into the pavement. Repeated impacts would cause the marker to become dislodged from flexible pavements by "popping out" a portion of the pavement. To reduce this problem, manufacturers developed the hot-applied asphalt based materials. These materials absorb some of the impact and reduce the damage experienced by the flexible pavement.

\section{Primers}

To ensure proper bonding of pavement markers such as thermoplastics to the pavement surface, it is often necessary to use a primer to prepare the pavement. The primer used on asphalt concrete pavements is normally a thermosetting adhesive which contains pigment reinforced synthetic rubber and synthetic plastic resin dissolved or dispersed in a solvent. Epoxy resin primers are normally used for portland cement concrete (PCC) pavements. The type of primer used for a particular marker on a particular pavement type should be consistent with the type recommended by the manufacturer.

\section{Description of Pavement Preparation Techniques}

The preparation of the pavement surface to be marked is a critical element in obtaining a quality product. The type of equipment required and the procedures employed to prepare the pavement and apply the marker are dependent upon the type of 
pavement marker being used and the type of pavement to which the marker will be applied. Corps of Engineer Guide Specification (CEGS) 02577 (US Army Corps of Engineers 1987) provides guidance on material specifications as well as pavement preparation and marker application.

There are three basic surfaces or substrates to which a new pavement marker may be applied. The first substrate is the old pavement marker of the residua of the old pavement marker with the exception of raised pavement markers. As a general rule, if the old marker is adhering adequately to the pavement surface then the new marker may be applied to the old marker. This is true only if the old marker is adhering to the pavement surface or, in the case of multiple marking layers, to each other and the new marker is compatible with the old marker. Often an old marker that is adhering well to the pavement surface makes a better substrate for application of the new marker because the marker/pavement bond has already been achieved.

The second type of surface is a bituminous pavement. To further complicate pavement preparation, the bituminous pavement may be a new or old pavement. The aggregates in a new bituminous pavement are covered with an oily film created by the bitumen or asphalt used in the $\mathrm{mix}$. This film prevents the marker from adhering to the pavement. New pavements are also more tender than their aged counterparts. If raised markers are placed on the new pavement, they are often lost due to traffic impacts on the marker causing the pavement under the marker to fail. This type of failure can be detected by the appearance of a small pothole where the marker was placed. Based on this information, it would seem desirable to let the pavement age before applying the marker; however, safety concerns required that the pavement be marked as soon as it is completed. To provide a marking that will adhere to new pavement, the surface must be properly prepared.

The aggregates in older bituminous pavements have often become polished and smooth as a result of traffic. The polished surfaces make it difficult to obtain an adequate bond of the 
marking material. Film caused by rain, rubber, and grime is also present on the roadway. This film acts as a barrier to prevent the marker from adhering to the pavement. Some type of preparation must be employed to remove any film buildup and to roughen polished aggregates to allow the new marker to bond to the pavement.

The third type of surface is PCC. As with the bituminous pavements, differences are noted between new pavements and old pavements. New PCC pavements will have surface films caused by curing compounds and laitance which prevent the marker from bonding to the pavement surface. Chemical reactions can also occur between the new pavement and the marker. For example, the alkaline nature of uncured concrete adversely affects alkyd paints causing them to be easily removed during the first big rainstorm (MCHRP 1988). Older PCC pavements will have a buildup of road film similar to bituminous pavements. Debris such as grime, tire rubber, and industry and agricultural products deposited on the pavement prevent bonding of the marker to the pavement surface.

\section{Techniques}

Just as there are several types of markers and various types of pavement surfaces, there are several methods that will satisfactorily prepare the pavement surface. The method selected to remove deteriorated markings also varies depending upon the type of marker being removed. The methods of pavement preparation and/or marker removal include (NCHRP 1988, Headquarters, Department of the Army 1987):

a. Compressed air.

b. Burning (excess oxygen).

c. Chemical removal.

d. Grinding.

e. Sandblasting.

f. Water blasting.

g. Wire brushing.

The removal of loose debris on the pavement surface using compressed air is one of the most common methods of pavement preparation. This method is effective in removing loose rocks 
and dust, but it will not remove road film or deteriorate markings. This method will provide the most benefit when used in conjunction with other methods.

Burning with excess oxygen is a modification to the old burning methods used to remove deteriorated markings. The old method consisted of burning propane or butane or both with air creating a flame temperature of approximately 2,000 degrees Fahrenheit. The direct flame was placed in contact with the marker causing combustion and removal. Some markers such as paints and thermoplastics contain a large quantity of fillers and noncombustible extenders which require long contact times with the flame. The slow rate of combustion of the markers allows heat from the flame to be absorbed into the pavement. The absorbed heat could result in spalling of PCC pavements and melting of bituminous pavements. By providing excess oxygen through a separate nozzle, the flame temperature is significantly increased thereby decreasing the time required to burn off the existing marker. The reduction in contact time also reduces the possibility of damaging the pavement. Once the marker has been burned, a residue of inert combustion products will remain on the pavement surface. The residue can normally be removed by sweeping or wire brushes. This method has been found effective in removing old marking films up to $20 \mathrm{mils}(0.5 \mathrm{~mm})$ thick and can remove foil tapes that have been exposed to traffic. As marker thicknesses increase above $20 \mathrm{mils}$, the method becomes less effective and other methods of removal should be considered (NCHRP 1988). Extreme care must be used during the operation of this equipment to ensure the flame does not remain stationary for too long. The excessive heat can easily damage pavements if the equipment is used improperly.

The use of chemicals as both a marker removal method and a pavement preparation method has been found to be very effective. In a Louisiana project (NCHRP 1988), chemical cleaning of PCC pavements was shown to increase the life of pavement markers by enhancing their adhesion to the pavement. The chemical, a 3 percent hydrofluoric acid solution, was sprayed onto the area to be 
marked, allowed to react, and was then washed off with water. The pavement surface was allowed to dry before the markers were applied. As one would expect, this method is more expensive and more hazardous than some of the other methods. Particular hazards include exposure of personnel to the acid solution, possible damage to vehicles that come in contact with the area before the acid has been removed, and exposure of the environment to the acid solution when it is washed off of the pavement.

Pavement markings which are $20 \mathrm{mils}$ thick or less can be removed very effectively using chemicals. The method for marker removal is the same as pavement preparation. Even though chemical removal and preparation methods are effective, much care and consideration must be used before approving a chemical method. With the ever increasing environmental concerns and in an effort to continually improve safety, it is recommended that chemical methods not be used.

Grinding is a relatively quick method for both pavement preparation and marker removal. As the name implies the grinding process prepares the pavement or removes the existing marker by an abrasive action. The method works well in removing any thickness of pavement marker. The one disadvantage this method has is that it can alter the surface texture and appearance of the pavement surface. This method is not recommended for marker removal if the area will not be remarked. If the area is remarked, alterations to the pavement surface will not be as noticeable since they will be covered up by the new marker. Grinding is not recommended for use when marking open-graded friction course or rough-textured PCC pavements.

Sandblasting is an effective method of pavement preparation and existing marker removal. In this method the sand is forced in contact with the pavement or the existing marker by compressed air. As the sand impacts the surface, the marker or road film is removed by the abrasive action. The effectiveness of sandblasting in removing existing markers is dependent upon the type of marker and the marker thickness. For example, sandblasting is very slow in removing foil backed tapes and has little effect on 
plastic tapes but removes paints and thermoplastics relatively easy. If care is exercised when sandblasting, the marker can be removed without damaging the pavement with respect to color and texture. The disadvantage of sandblasting is the amount of equipment required and the fact that used sand is left on the pavement surface. Some areas no longer allow the use of sandblasting because blowing sand and dust may violate atmospheric pollution statues or may drift into areas where it would be objectionable.

Water blasting consists of directing a high-pressure water jet at the pavement surface. It can be used for surface preparation or marker removal. A modification to the water blasting technique can be achieved by adding sand to the water. This method is often termed hydroblasting (NCHRP 1988). Water blasting and hydroblasting yield similar results to sandblasting, except when water blasting is used. The pavement must be allowed to dry before work can continue. The effectiveness of maker or road film removal is dependent upon the thickness of the marker or film being removed and the pressure of the water jet. Normal operating pressures are 2,000 to $10,000 \mathrm{psi}$ ( 14 to $70 \mathrm{MPa}$ ).

Wire brushing is one of the simplest methods of surface preparation, but it is not effective in removing existing markers. The effectiveness of wire brushing for pavement preparation is dependent upon the condition of the brushes and the thickness of the road film. Worn brushes will not remove the road film as effectively as new brushes. It is therefore important to inspect the brushes on a regular basis to ensure the brushes are performing adequately. "Regular basis" will be dependent upon the type and texture of the pavement and should be determined at the beginning of each project.

Regardless of which method or methods are chosen to remove existing markers, it is important to examine the prepared area in the daytime and at night. often a marker that appears to be removed during daylight hours will be visible under the reflection of headlights at night. Glass beads can be retained very easily in rough textured pavements. The reflection created by 
the glass beads can create confusion for traffic if the area is being marked in a different pattern. If the area is to be remarked in the same pattern, the remaining glass beads may not create a problem at all.

Table 1 presents the cost effectiveness of the various pavement preparation and marker removal techniques. This table can be used to provide general guidance when selecting the method or methods to be used for a project.

Table 1 indicates that wire brushing is the most costeffective method of pavement preparation followed by grinding, sandblasting, and water blasting. The significant advantage wire brushing exhibits over the other methods could be greatly reduced as the brushes become worn during use. Burning with excess oxygen is the most cost-effective method of strip removal followed by sandblasting, grinding, and water blasting. Sandblasting is

Table 1

Relative Cost Effectiveness of Various Surface Preparation and Stripe Removal Methods

\begin{tabular}{|c|c|c|c|c|c|c|}
\hline \multirow[b]{2}{*}{ Method } & \multicolumn{3}{|c|}{ Surface Preparation } & \multicolumn{3}{|c|}{ Stripe Removal } \\
\hline & $\underline{\text { Cost* }}$ & $\underline{\operatorname{Eff} . * \star}$ & $\begin{array}{c}\text { Cost/ } \\
\text { Eff. }\end{array}$ & $\underline{\text { Cost* }}$ & $\underline{\text { Eff.** }}$ & $\begin{array}{c}\text { Cost/ } \\
\text { Eff. }\end{array}$ \\
\hline Blowing & 01 & 0.05 & 20.0 & 01 & 0.01 & 200.0 \\
\hline Burning (excess $\mathrm{O}_{2}$ ) & 24 & 2.00 & 12.0 & 24 & 8.00 & 3.0 \\
\hline Chemical & 54 & 6.00 & 9.0 & 54 & 5.00 & 10.8 \\
\hline Grinding & 36 & 9.00 & 4.0 & 36 & 6.00 & 6.0 \\
\hline Sandblasting & 52 & 10.00 & 5.2 & 52 & 10.00 & 5.2 \\
\hline Water blasting & 38 & 7.00 & 5.4 & 38 & 5.00 & 7.6 \\
\hline Wire brushing & 10 & 7.00 & 1.7 & 10 & 0.50 & 20.0 \\
\hline
\end{tabular}

Note: This table is taken from TRB, National Cooperative Highway Research Program Synthesis of Highway Practice 138, 1988, "Pavement Markings: Materials and Application for Extended Service Life," p. 10.

* Cost $=$ cents per foot.

** Effectiveness: Does not remove material--harms pavement $=0$.

Removes material--does not harm pavement $=10$. 
the most cost effective overall, providing good stripe removal and pavement preparation techniques.

There is a wide range of equipment used to perform the pavement preparation and stripe removal methods. To determine if the equipment will perform adequately for a given task, it is recommended that a test section be required. Visual inspection of the test section will normally be adequate in determining if the equipment is accomplishing the desired task without damaging the pavement.

Equipment

The type of equipment and procedures used to apply a traffic marker are dependent upon the marker type and location. The recommended thickness of paint and thermoplastic markers and the spacing requirements for skip lines and raised reflective markers are provided in CEGS 02577 and in the MUTCD. Safety devices which are required on the marking equipment as well as traffic control guidelines are also provided in the MUTCD.

Traffic paint equipment. The equipment used to apply traffic paints can be either self-propelled (Photo 1), portable (Photo 2), or in instances when equipment can not be used in the area being marked, hand-held (Photo 3 ). Air pressure is the most common method of forcing the paint from the storage tank, atomizing it through a nozzle, and applying it to the pavement surface. The wet-film thickness of the paint will be affected by vehicle speed, paint temperature and viscosity, and the hydraulic head of paint in the storage tank. If the vehicle slows down, the wetfilm thickness increases; if it speeds up, the wet-film thickness is reduced.

The paint storage tanks on the application equipment should be equipped with mechanical agitators. The agitation will ensure the paint remains homogeneous and will prevent localized hot spots of hot-applied paints. Strainers should also be installed in the paint lines to prevent the spray from becoming clogged. Pressure gages should be located in a position to allow easy reading. 
Thermoplastic application equipment. Thermoplastics may be applied to the pavement surface by spraying techniques or by extrusion. The equipment and techniques used to spray thermoplastics are almost identical to those used for paints. With the extrusion method, the molten thermoplastic is poured onto the pavement surface and formed into a line by a shaping die (Photo 4). It is important that either type of equipment, spray, or extrusion, continually mix the material to provide homogeneity and to prevent uneven heating and localized hot spots. An oil bath heating media should be used instead of direct flame heating to further minimize the possibility of uneven heating.

The thermoplastic application equipment can be mobile or portable. Mobile thermoplastic application equipment is defined as a truck-mounted, self-contained pavement marking machine while portable is defined as hand-operated equipment designed to apply stop bars, legends, arrows, and short lengths of line (US Army Corps of Engineers 1987). The portable equipment normally only extrudes material on the pavement but the mobile unit can spray or extrude the material. The normal application range for thermoplastics is 375 to 425 degrees Fahrenheit so the application equipment should be able to maintain this temperature range. Thermometers and gages should be located so that they are easily visible to quality control and operator personnel.

Reflective media dispensers. Reflective media or bead dispensers (Photo 5) are attached to the marker application equipment and are operated automatically and simultaneously with the marker applicator. The bead dispensers can be gravity fed or pneumatically operated. The dispenser should be designed to provide uniform coverage over the entire length and width of the stripe. The flow of beads should begin shortly before the application of the stripe and should continue a short distance after the application of the stripe. This technique will ensure that the entire stripe has been covered.

Traffic tape application equipment. Mechanical tape application equipment is designed to apply precoated pressure sensitive tapes. The mechanical equipment is usually used to apply 
center lines, fog lines or edge lines, and stop bars. Legends and arrows are normally placed by hand using hand tools to apply the adhesive to the roadway and seat the marker to the pavement (Photo 6).

\section{Description of Pavement Marking Techniques}

Once the pavement surface has been prepared, the appropriate primer is applied to the pavement surface, the primer is allowed to cure, and the marker is applied to the pavement. The pavement temperature should be 40 degrees Fahrenheit and rising to apply traffic paints and thermoplastics while a pavement temperature of 60 degrees and rising is required for preformed tapes. It is important that the pavement surface be free of moisture when applying the markers to allow them to bond to the pavement. This is especially true when applying thermoplastic markers. The heat of a thermoplastic material will cause moisture to be drawn from the pavement and form blisters and delaminated areas in the thermoplastic. A simple method to determine if the pavement is dry enough to apply a thermoplastic is to place a square piece of plastic or tar paper on the pavement surface and pour a small quantity of thermoplastic onto square. The thermoplastic is allowed to cool, the square is removed from the pavement surface and examined. If the underside of the square does not have any condensation present, then the pavement is dry enough to mark.

The application of paints and thermoplastics is simple. The material is sprayed or extruded onto the pavement surface to the thickness specified. The distance of the spray nozzles from the pavement surface must be adjusted to ensure the markers have clean sharp edges. The thickness of sprayed-on markers is adjusted by the speed of the equipment while the thickness of extruded markers is adjusted by a gate on the die.

The application of tapes and button markers is also relatively simple, but it may be accomplished using different methods. The materials may be either applied to the pavement surface or recessed into the pavement. In an effort to obtain longer 
field performance from pavement markers, some state DOT's experimented with recessing or inlaying tapes and buttons. These techniques are no longer experimental and have been used extensively by various DOT's.

The most common method of inlaying tape materials is to roll the tape into a flexible pavement as it is being constructed. The edge line and center line markings are carefully placed onto the fresh asphalt cement concrete after initial compaction. As finish rolling is being completed, the tape is inlaid into the pavement by the weight of the roller.

The most common method of recessing button markers is to grind a small channel into the pavement and placing the marker at the bottom of the channel. The channel width and depth are dependent upon the size of marker being used. This method can be used in both PCC and asphalt cement pavements and increases the life of the marker by eliminating the marker's exposure to traffic. The disadvantage of this method is a reduction in delineation. Since the marker is recessed, it is not as visible as a marker which is not recessed and water can be retained in the channel eliminating the marker's effectiveness in rainy weather.

The more prominent method of applying tapes and button markers is to place them on the pavement surface. Tapes are placed on the pavement surface and seated using hand-rollers. The adhesive used to bond the marker is applied to the pavement surface and then the marker is pressed into the adhesive. A typical method of seating the raised marker is for one member of the crew to step on it after it is placed on the pavement.

\section{Application}

The use of pavement markings is applicable to all rigid and flexible pavements that are exposed to any kind of traffic. The markings are used to control the flow of traffic and increase safety by providing directional guidance and regulatory and warning information. 


\section{Limitations/Disadvantages}

The limitations or disadvantages of a specific pavement marking material will be dependent upon the geographic location where it is being used. Performance evaluations conducted by state agencies have presented conflicting results indicating that a pavement preparation technique or marking application procedure that provides acceptable results in one state, county, or city may provide totally unacceptable results when used in another area. The differences in climate, pavement substrate, and environmental constraints explain why each state and city agency has its own specifications and practices for materials and application procedures.

Limitations concerning color, shape, spacing, widths, and reflectance requirements for nonairfield pavement marking applications are provided in MUTCD. TM 5-823-4 provides this information for US Army airfields, and AFR 88-16 provides this information for US Air Force airfields.

\section{FEAP Demonstration/Implementation Sites}

There were two demonstration projects conducted between 1988 and 1990. The 1988 project site was Fort Bragg, NC. Two types of pavement markings, a traffic paint and a thermoplastic, were demonstrated at this site. A primary roadway was stripped using the thermoplastic, and secondary roads were stripped using the paint. Glass beads were applied to both marking materials for reflectivity. All of the roads that were stripped were asphalt pavements. The primary road was an existing pavement, and the stripping on the secondary roads was accomplished in conjunction with an overlay project. The pavement preparation method used for both pavement marking types was cleaning with compressed air. Approximately 14 days were allowed to elapse before the paint was sprayed onto the asphalt overlay. As of 1990, the markings were still delineating the roadways satisfactorily during daylight and no restripping work had been undertaken. 
The 1990 project site was Fort Lewis, WA. Two types of pavement markings, a reflective tape and a raised reflective marker, were demonstrated at this site. Both marking types were used on primary roads, and the pavement preparation method used for both markings was cleaning with compressed air. An adhesive material was applied to the pavement surface before the tape material was placed. A 100-pound roller was then used to seat the tape in-place. A hot-applied, asphalt-based adhesive material was used to bond the raised reflective markers to the pavement surface. After the pavement was cleaned with compressed air, the adhesive was applied to the pavement and the marker was placed in the adhesive. The operator would then stand on the marker to seat it. As of 1991, the markings were still delineating the roads satisfactorily and no restripping work had been undertaken. This is a considerable improvement over the paint materials that had previously been used at Fort Lewis. Base personnel stated that the paint materials would not provide satisfactory delineation after 4 months, and the roads were repainted annually.

\section{Life-Cycle Costs and Benefits}

The monetary benefits realized by selecting the appropriate marking for a specific installation and properly applying that marking are difficult to analyze. If one assumes a 6-year life cycle for the markings, then the cost at the end of 6 years for paints and thermoplastics will be similar. This assumes a 4 month life of the paint and repainting after 4 months, and a 6 year life of thermoplastics. This does not include the costs related to vehicle accidents that could potentially occur if the pavements are not properly delineated.

The 4-month life cycle assumed for the paint seems reasonable from conversations with personnel from Fort Lewis; however, the assumption of repainting every 4 months seems unlikely. Therefore, there are approximately 8 months per year in which the 
pavements may not properly delineate, increasing the potential for accidents.

\section{Costs}

The cost of the installed marking material will vary depending upon the type of marking that is selected. Paints typically cost approximately $\$ 0.03$ per linear foot for a 4-inch strip, thermoplastics cost approximately $\$ 0.40$ per linear foot for a 4-inch strip, and tapes typically cost approximately $\$ 1.25$ per linear foot for a 4 -inch strip. The actual cost will vary for different geographical areas depending upon the local labor market. The project specifications currently used by the Department of the Army allow the preparation options described in "Description of Pavement Preparation Techniques." So an increase in contract price is not expected.

\section{Advantages/Benefits}

Pavement marking materials are designed to improve traffic flow and improve vehicle and pedestrian safety. Therefore, by selecting the appropriate marking and properly preparing the pavement and applying the marking, the life of that marking can be increased. Although monetary savings would be expected by increasing the marking life, the biggest advantage may be the prevention of accidents caused by improperly delineated pavements. 


\section{Potential Funding Sources}

Typically, installations fund the implementation of Pavement and Railroad technologies out of their annual budgets. However, the annual budget is always underfunded and normally the pavements and railroads projects do not compete well with other high visibility/high interest type projects. As a result, it is in ones best interest to seek all of the funds possible from other sources when the project merits the action. Listed below are some sources commonly pursued to fund projects.

a. Productivity program. See AR 5-4, Department of the Army Productivity Improvement Program for guidance to determine if the project qualifies for this type funding.

b. Facilities Engineering Application Program (FEAP). In the past, a number of pavement and railroad maintenance projects located at various installations were funded with FEAP demonstration funds. At that time, emphasis was placed on demonstrating new technologies to the Directorate of Engineering and Housing ( $D E H$ ) community. Now that these technologies have been demonstrated, the installations will be responsible for funding their projects through other sources. However, emphasis concerning the direction of FEAP may change in the future; therefore, do not rule out FEAP as a source of funding.

c. Special programs. Examples of these are as follows:

(1) FORSCOM mobilization plan which may include rehabilitation or enlargement of parking areas and the reinforcement of bridges.

(2) Safety program which may include the repair of unsafe/deteriorated railroads at crossings and in ammunition storage areas.

(3) Security upgrade which may include the repair or enlargement of fencing.

d. Reimbursable customer. Examples of this source are roads to special function areas such as family housing or schools and airfield pavements required to support logistical operations.

e. Special requests from MACOMS.

f. Year end funds. This type funding should be coordinated with the MACOMS to ensure that the funds will not be lost after a contract is advertised. 
g. Operations and Maintenance Army (OMA). These are the normal funds used for funding pavement and railroad projects.

\section{Technology Components and Sources}

Components of this technology which must be procured for pavement marking are project design (may be accomplished in-house or contracted out), contractor or in-house crew to perform existing marking removal, pavement preparation, and marking application.

All of the items used in pavement marking are conventional materials and procedures; therefore, no special materials or procedures are required.

\section{Procurement Documents}

A Corps of Engineers guide specification, Department of the Army technical manual, Department of the Air Force standards, and Department of Transportation manual are available to provide assistance in completing project specifications. The available guidance includes:

a. CEGS-02577, "Pavement Markings."

b. Department of the Army TM 5-823-4, "Marking of Army Airfield-Heliport Operational and Maintenance Facilities."

c. Department of the Air Force AFR 88-16, "Standards for Marking Airfields."

d. Department of Transportation, Federal Highway Administration, "Manual on Uniform Traffic Control Devices."

e. Department of Transportation, Federal Highway Administration, "Roadway Delineation Practices Handbook," Implementation Package FHWA-IP-81-5.

\section{Procurement Scheduling}

Pavement marking work should be scheduled during the spring, summer, or fall of the year. 


\section{Initial Implementation}

\section{Equipment}

The equipment required for pavement marking is described in PART II. This equipment is standard construction equipment; therefore, no special equipment is required.

\section{Material}

The pavement marking material required for a project will be dependent upon the pavement type and the type of traffic to which the pavement is exposed. Guidance on selecting the type of material that should be used for a general area is provided in "Description of Pavement Marking Materials." The manufacturer's literature should be consulted when selecting a primer.

\section{Personnel}

Personnel familiar with the procedures of pavement marking should be employed for marking projects. At Fort Bragg, the work was contracted out. At Fort Lewis, the work was conducted by in-house crews.

\section{Procedure}

The procedures used to prepare the pavement and apply the marking will be dependent upon the type of pavement being marked and the type of material being used. Guidance on specific procedures are outlined in PART II.

\section{operation and Maintenance}

Pavement marking is in itself basically considered a maintenance activity. By incorporating the correct techniques for pavement marking, it is estimated that maintenance costs can be reduced, and safety of vehicle and pedestrian traffic can be increased. 


\section{Service and Support Requirements}

No special services or support is required to implement or maintain this technology.

\section{Performance Monitoring}

Installation personnel can monitor and measure the performance of pavement marking materials by conducting visual inspections of the area that has been marked. The best method of inspection is to inspect the area in both daylight and at nighttime to ensure proper delineation is being maintained. 


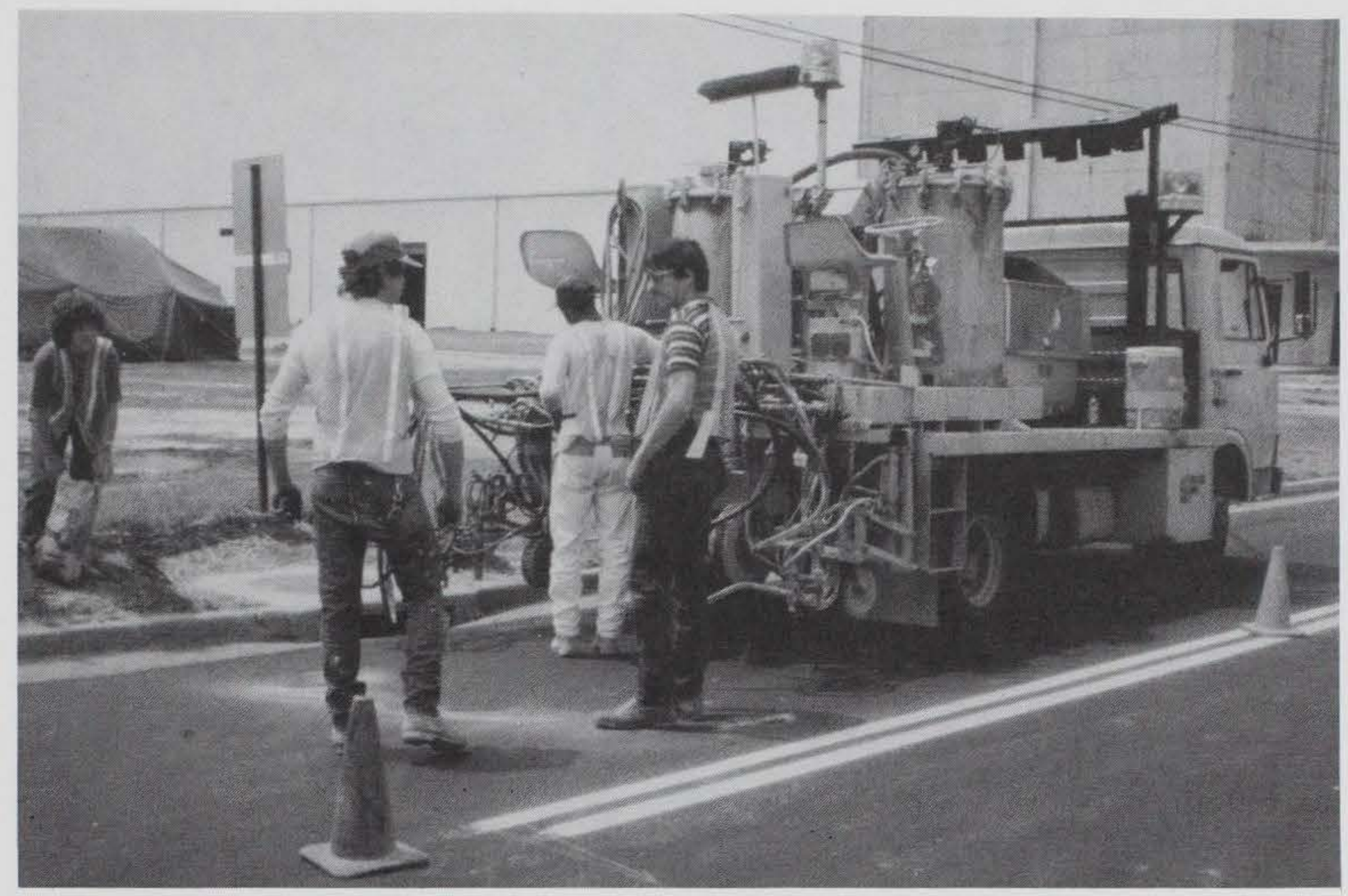

Photo 1. Self-propelled paint applicator

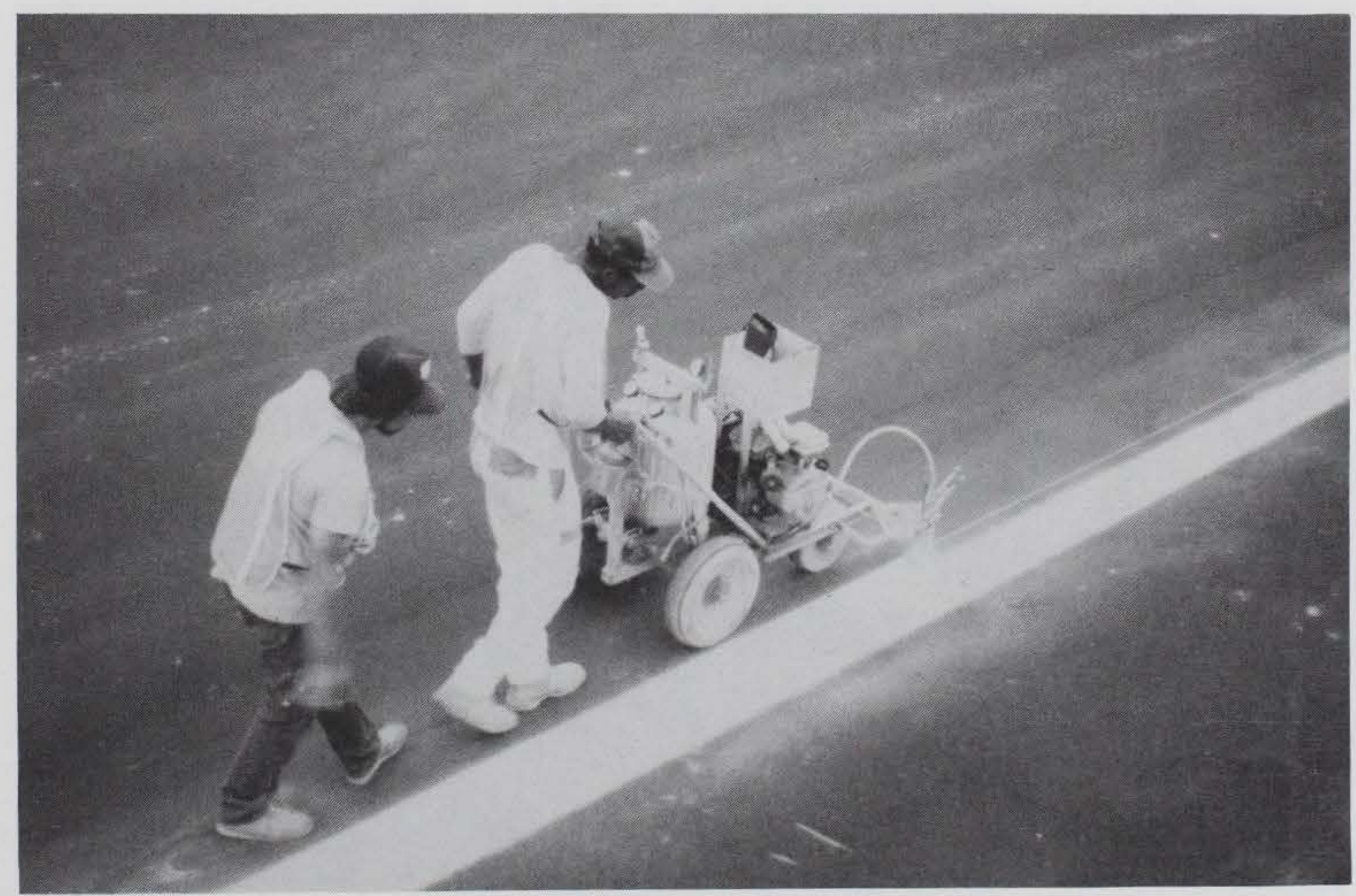

Photo 2. Portable paint applicator 


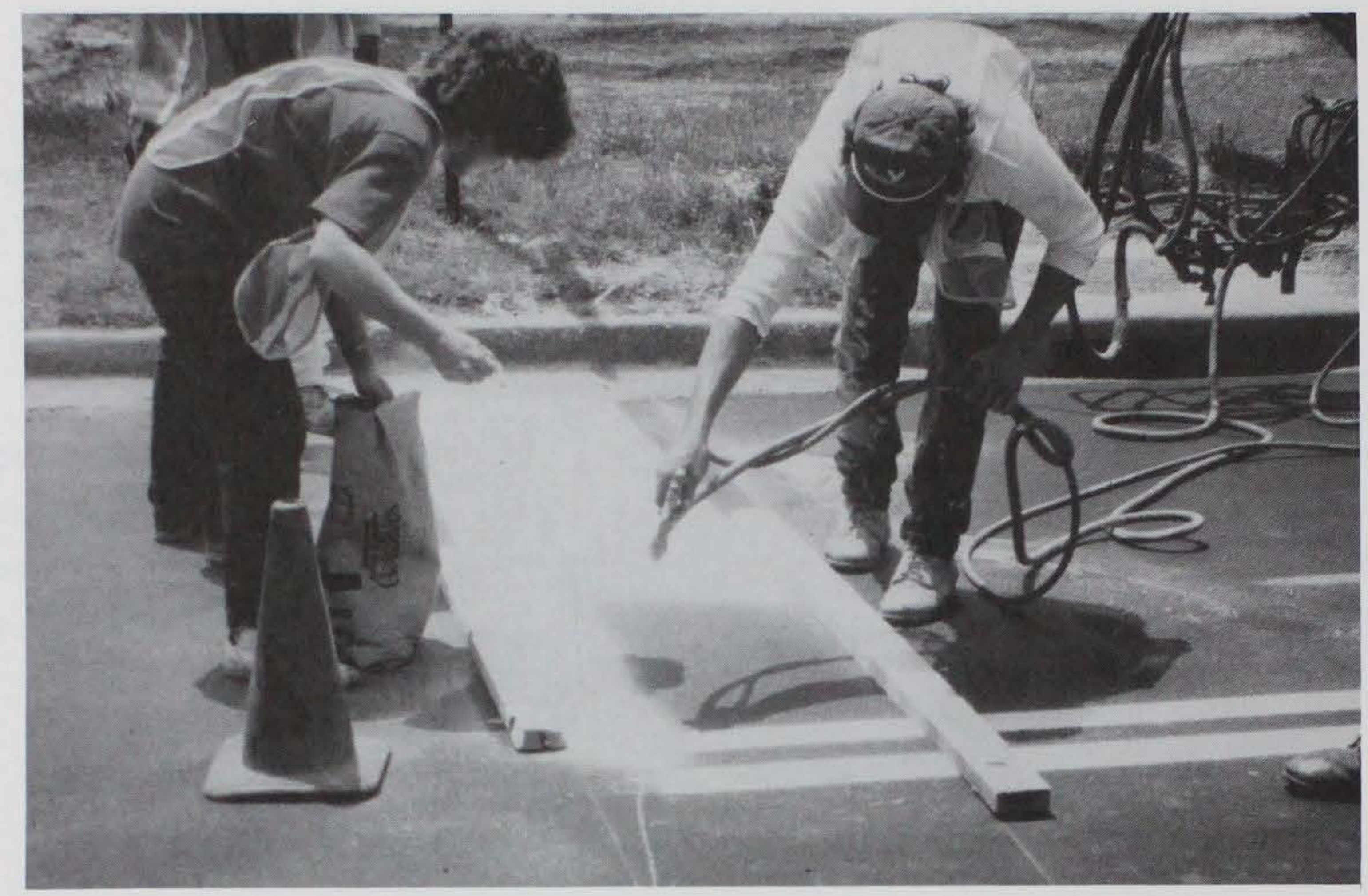

Photo 3. Hand-held paint applicator

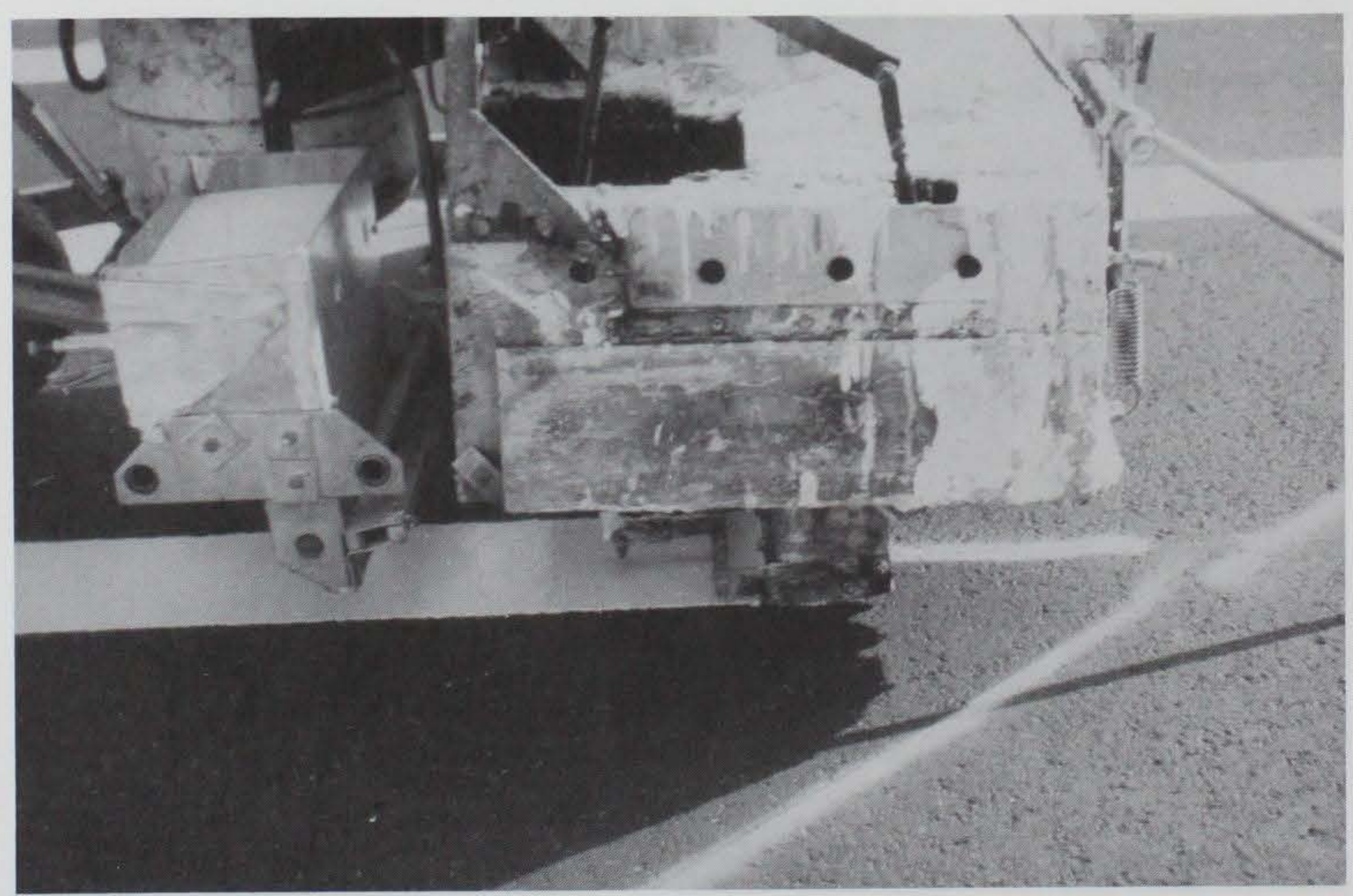

Photo 4. Shaping die used for thermoplastic application 


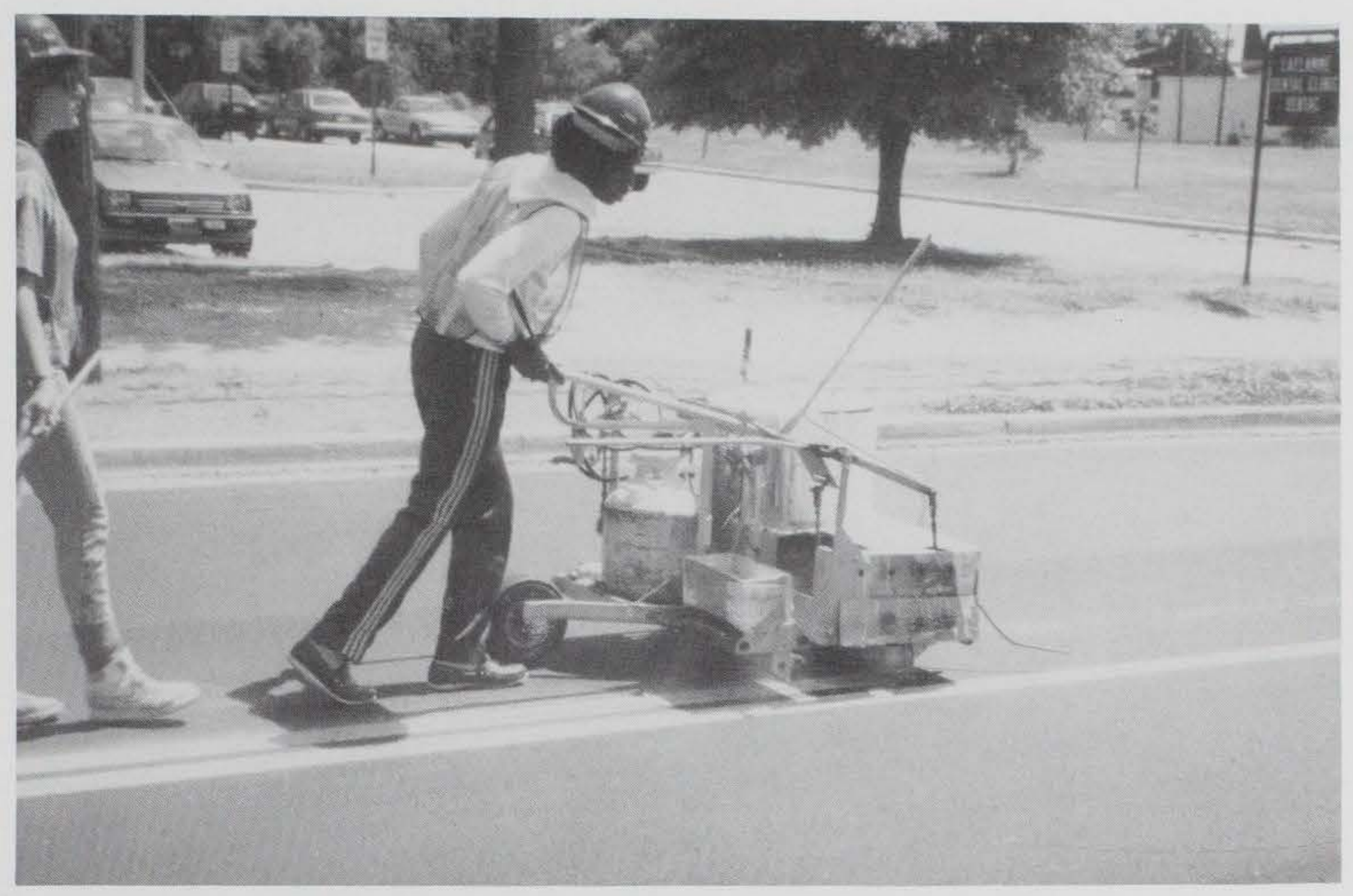

Photo 5. Thermoplastic applicator with bead dispenser attached

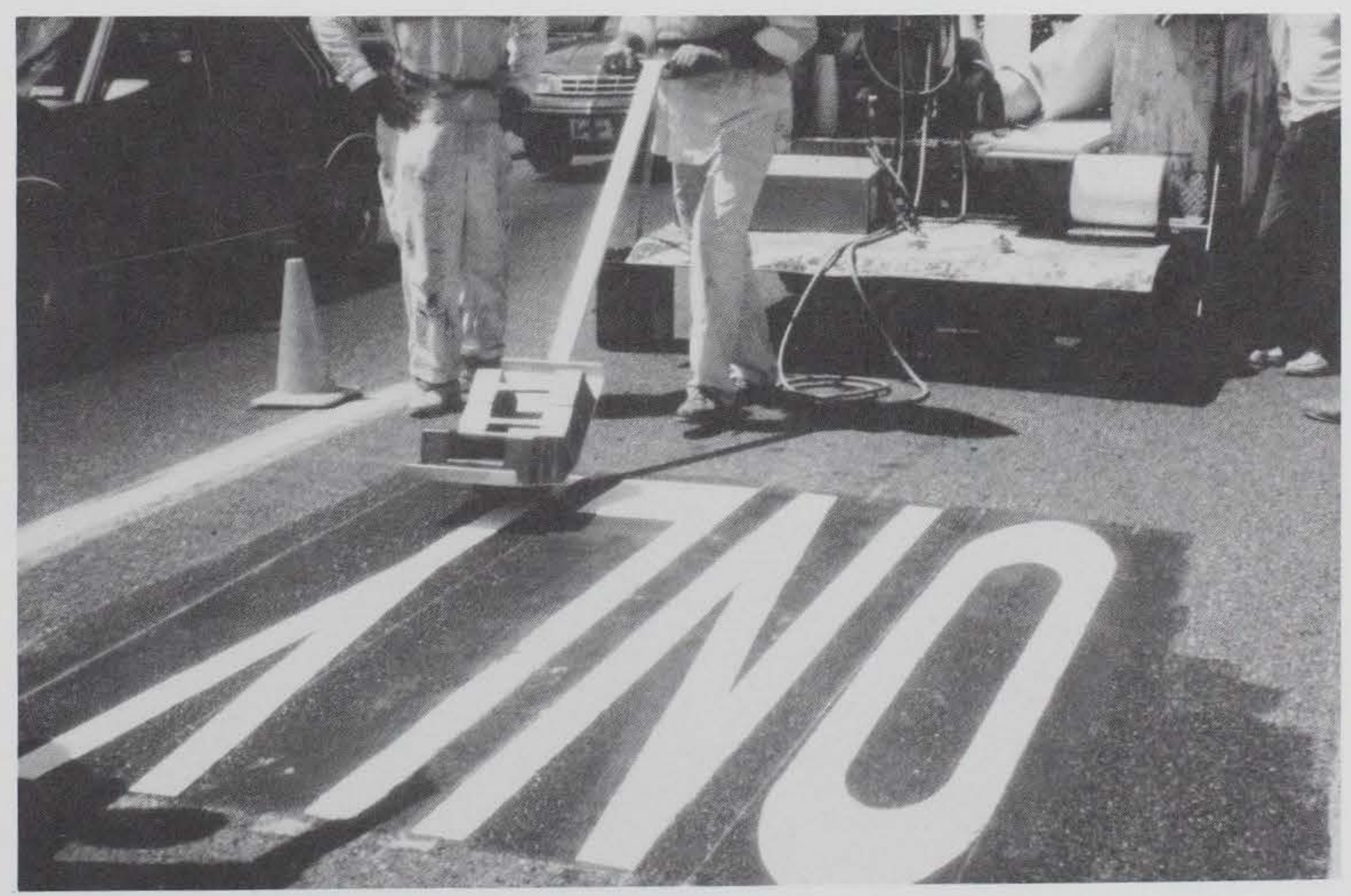

Photo 6. Sealing traffic tape using 150-lb roller 
APPENDIX A: REFERENCES 
Better Roads. 1989 (Dec). "Striping and Marking: What Works Best?"

Bryden, James E., and Gurney, Gary F. 1984. "Pavement Marking Materials: New York's Experience," Transportation Research Record 979, Work-Zone Safety and Maintenance Management, Transportation Research Board, National Research Council.

Headquarters, Department of the Army. 1987 (Jul). "Marking of Army Airfield-Heliport Operational and Maintenance Facilities," Technical Manual TM 5-823-4, Washington, DC.

Headquarters, Department of the Air Force. 1988 (Oct). "Standards for Marking Airfields," Air Force Regulation AFR 88-16, Washington, DC.

National Cooperative Highway Research Program (NCHRP) Synthesis of Highway Practice 138 (1988) - "Pavement Marking: Materials and Application for Extended Service Life." 1988 (Jun). Transportation Research Board, National Research Council, Washington, DC.

Organization for Economic Co-Operation and Development, Road Research. 1975 (Feb). "Road Marking and Delineation," Paris, France.

US Army Corps of Engineers Guide Specification (CEGS) 02577. 1987 (Feb). "Pavement Markings," Washington, DC.

US Department of Transportation, Federal Highway Administration. 1988. "Manual on Uniform Traffic Control Devices," Washington, DC.

1981 (Sep). "Roadway Delineation Practices Handbook," Implementation Package FHWA-IP-81-5, Washington, DC. - 1976 (May). "State of the Art on Roadway Delineation Systems," Report No. FHWA-RD-76-73, Federal Highway Administration offices of Research and Development, Washington, DC. 